\title{
PROCEDIMENTOS DE ANÁLISE CONSTRASTIVA COMO CONTRIBUIÇÕES PARA AAMPLIAÇÃO DO VOCABULÁRIO EM INGLÊS INSTRUMENTAL
}

\section{Maria Inez Matoso Silveira (UFAL)}

Resumo: Este artigo aborda e discute a importância do domínio do vocabulário na aprendizagem de uma língua estrangeira, e propõe alguns procedimentos de natureza contrastiva envolvendo o processo de formação de palavras (derivação) e os radicais gregos e latinos, com vistas à ampliação da competência lexical entre alunos de inglês instrumental.

Palavras-Chave: Análise contrastiva; Processo derivacional; Ampliação do vocabulário.

$* * *$

\section{INTRODUÇÃO}

$\mathrm{Na}$ visão sóciointeracional da linguagem, há um consenso de que as competências lexical e gramatical são componentes essenciais da competência comunicativa. Desse modo, devemos considerar que, para dominar um idioma, o indivíduo deve conhecer não apenas a estrutura morfossintática da língua e um acervo lexical compativel com as suas necessidades de sobrevivência e de contínuo desenvolvimento intelectual, mas também, ele precisa conhecer as fórmulas sociais e os usos da língua em situações concretas da vida, de conformidade com os costumes, convenções e práticas culturais que ocorrem na dinâmica das atividades humanas. Daí depreende-se que o conhecimento comunicativo não exclui; pelo contrário, inclui, e até depende do conhecimento gramatical e do conhecimento lexical da língua.

Neste artigo, enfatizaremos a competência lexical e sua importância para a aprendizagem e para o gradativo domínio da língua estrangeira, aqui no caso, da língua inglesa. Essa preocupação se explica por conta de uma constatação desenvolvida ao longo da minha prática pedagógica no ensino de inglês, em escolas regulares e em institutos especializados em ensino de idiomas. Tal constatação foi fortalecida durante as experiências de ensino de inglês instrumental (ESP), em cursos técnicos de nível médio, em cursos de graduação na universidade e mesmo entre alunos de cursos de pós-graduaçào.

Com efeito, verifiquei que a pobreza de vocabulário do aluno é uma das causas do pouco progresso e até da evasão entre alunos dessa modalidade de ensino. Vários fatores podem ser apontados para o fraco domínio de itens lexicais na língua estrangeira; e um deles pode ser a desatenção, o desinteresse, 
pela questão do vocabulário a partir da própria língua materna. É provável que essa atitude seja transferida para aprendizagem da lingua estrangeira, obviamente, de forma inconsciente.

Outro problema imediatamente relacionado ao acima citado é a carência, por parte do aluno, de uma reflexão ou consciência metalingüística necessária ao estudo da linguagem humana. Noutras palavras, há a ausência de uma metacognição ${ }^{1}$ sobre os elementos fônicos e morfossintáticos da própria língua materna, o que dificulta o entendimento desses mesmos fenômenos na língua estrangeira, especialmente daqueles elementos necessários à percepçào do vocábulo, sua estrutura e suas implicações semânticas dentro da frase.

Em ambos os casos, pode ser de grande valia a utilizaçào de alguns recursos e procedimentos de ensino que venham a ajudar o aluno a despertar para a importância de entender os aspectos estruturo-gramaticais e lexicais da língua materna como suporte importante para entender o funcionamento da língua estrangeira, e vice-versa. ${ }^{2}$ Naturalmente, os aludidos procedimentos de ensino para tornar o aluno consciente dos fatos gramaticais e léxico-semânticos de ambas as línguas são de natureza contrastiva. Mas, antes de entrarmos efetivamente na discussão desses recursos, convém desenvolvermos algumas reflexões a respeito da aquisição, aprendizagem e ensino do vocabulário de uma língua.

\section{OS ESTUDOS SOBRE VOCABULÁRIO E SUAS IMPLICAÇÕES NO ENSINO E NA APRENDIZAGEM DE LINGUAS ESTRANGEIRAS}

As investigações a respeito do vocabulário reportam-se ao estudo do léxico de determinada língua - a Lexicologia. Essa disciplina mantém estreitas relaçòes com a Semântica, que pode ser definida, em princípio, como o estudo dos significados e das maneiras sistemáticas como esses significados sào expressos na língua. A relevância do léxico nos estudos lingüísticos e suas aplicações na educação lingüística tem variado conforme as concepçòes de

\footnotetext{
Ultumanente, tem-se intensificado o interessic pelos processos cognitives a metacognitios relativos à aquisição e aprendizagem de linguas maternas e estrangeiras. Num plano mais abrangente, as relaçóes entre linguagem a crignçâo estão despertando o interesse de vários cientistas, a exemplo de Ungerer (2016).

2 Fimbora não muite freqüente, ocorre de se ouvir algumas pessoas dizerem que passaram a perceber a se interessar peles clementos gramaticais, lexicas e semântıcos da sua lingua materna a partir do estudo da língua estrangeira. Aliás, esta é uma das grandes contribuiçós que o ensine e aprendizagem 16 línguas tem dado a muitos dinyueles que se dedicam a essa atridade. No nosso entender, isso deve ser estimulades
} 
linguagem e as abordagens de ensino que vêm se desenvolvendo ao longo dos tempos (SILVEIRA, 1999).

Recentemente, a questão lexical tem merecido muita atençào, com reflexos bastante significativos no ensino de idiomas. ${ }^{3}$ De fato, está ocorrendo uma revivescência da importância do léxico no panorama atual do ensino de línguas. Como diz Leffa (2000, p.17),

Se alguém, ao estudar uma língua estrangeira, fosse obrigado a optar entre o léxico e a sintaxe, certamente escolheria o léxico: compreenderia mais um texto identificando seu vocabulário do que conlecendo sua sintaxe. Da mesma maneira, se alguém tiver de escolher entre uma gramática e um dicionário, certamente escollherá o dicionário. Língua não é só léxico, mas o léxico é o elemento que melhor a caracteriza e a distingue das outras.

Saber uma palavra não é tão simples como pode parecer à primeira vista. Esse conhecimento implica o desenvolvimento de uma certa competência lexical, já referida anteriormente, que se concretiza através do uso adequado dessa palavra, e da consciência dos vários significados que ela pode assumir nas diversas situaçòes comunicativas. Essa habilidade leva o indivíduo a se familiarizar com o fenômeno da polissemia, que é uma das mais importantes propriedades da linguagem humana.

Convém salientar que conhecer e utilizar adequadamente o vocabulário de uma determinada língua significa conhecer os seus processos de formação de palavras e seus processos de sinonímia, antonímia, heteronímia, hiperonímia e hiponímia. Esse conhecimento pode ser visto como uma aquisição razoavelmente eficaz que se constrói a partir da própria competência lingüística do indivíduo (a chamada gramática natural) e do uso diversificado e cada vez mais elaborado da língua, através das interações sociais. Mas, para que esse conhecimento se torne consciente e monitorável, é necessária a intervenção pedagógica, ao longo da escolaridade, nào só na língua materna, como na língua estrangeira.

As polêmicas a respeito da aprendizagem do vocabulário dividem-se, primeiramente, segundo Hatch \& Brown (1995), entre a aprendizagem incidental e a aprendizagem intencional. A primeira forma ocorre naturalmente, no contato do usuário com as modalidades falada e escrita tanto da língua materna, quanto

Convém registrar aqui a chamada Abordagem I.exical (Lexical Approach) defendida inicialmente por Michacl J cuvis $(1993,1997)$ e que só recentemente começou a a ser disseminada nos centros de ensino de idiomas no Brasil. 
da língua estrangeira. ${ }^{+}$Sabe-se que a aprendizagem intencional do vocabulário ocorre muito na língua estrangeira, já que a maioria dos métodos de ensino de idiomas dão uma atenção especial à questão. Já na língua materna, essa aprendizagem intencional tem sido praticada através da leitura e compreensão de textos nos livros didáticos.

Outra discussào relevante, que gira em torno do ensino-aprendizagem do vocabulário, é a dicotomia entre vocabulário ativo e vocabulário passivo (também chamados de vocabulário produtivo e vocabulário receptivo). Apesar de haver algumas controvérsias a respeito, o fato é que todos nós entendemos e reconhecemos palavras que nunca usamos nas nossas interaçòes discursivas. Esse vocabulário passivo é muito útil nas atividades de recepção de textos. Obviamente, conforme a necessidade, boa parte desse vocabulário passivo pode tornar-se ativo.

A especificidade do conhecimento de uma palavra por parte de qualquer indivíduo depende de sua motivação, de seus desejos e necessidades de uso dessa palavra. A aquisição do vocabulário nào parece funcionar como uma passagem automática entre o não-conhecimento e o conhecimento de palavras. Parece haver uma dinâmica, ou melhor, um continutum entre o contato com a palavra e o seu conhecimento efetivo. $\mathrm{O}$ aprendiz pode situar-se em algum ponto desse continuum. Nessa perspectiva, e segundo Hatch \& Brown (1995), as pesquisas sobre aquisição de vocabulário têm apontado um modelo cujas estratégias ocorrem em cinco passos seqüenciados, quais sejam:

1. Acesso a fontes que proporcionem o contato com palavras novas;

2. Formaçào de imagens visuais e fonológicas dessas novas palavras;

3. Compreensão do(s) significado(s) dessas palavras;

4. Esforço deliberado para reter essas palavras na memória através do estabelecimento de conexòes entre os seus significados nos esquemas conceptuais cognitivos;

5. Uso efetivo dessas palavras em contextos significativos.

Algumas aplicações de teorias lingüísticas têm contribuído muito para o ensino-aprendizagem do vocabulário. As mais relevantes sào a análise dos traf̧os semanticos (semantic feature analysis) oriunda da teoria desenvolvida por

A chamada aprendizagem incredental relaciona-se ao processo de aguisiçäo de segunda lingua defendido por Stephen Krashen (1981).

Várals técnicas de ensino-aprendizagem do vocabulário foram sendo criadas ao longo do desenvolvimento das abordagens, métodos e técnicas de ensino. As mais antigas sào as listas de palavras, os glossários, precnchimento de lacunas em frases, até os procedimentos mais lúdicus, como joges, criptogramas, etc. 
Katz e Fodor, e a teoria dos campos semânticos, referidos por Paiva (2004, p.11) como mapas conceituais. Como ilustraçào dessas aplicaçòes, podemos citar, por exemplo, uma atividade em que, num conjunto de palavras dadas, possam ser verificados os traços semânticos que elas têm ou não têm em comum (se são concretas ou abstratas; se têm traços humanos ou não-humanos, etc.).

Essas atividades e outras similares ajudam o aluno a organizar metacognitivamente as suas redes conceptuais e estratégias de aquisição, manutenção e ampliação do vocabulário, estimulando o aprendiz a relacionar as palavras aos seus esquemas mentais, num esforço cognitivo que vai se tornando cada vez mais ágil, até tornar-se uma habilidade cognitiva de grande valia em todas as atividades humanas. Obviamente, essa habilidade só se instala se as novas palavras adquiridas forem utilizadas em contextos significativos, promovendo a interação entre a memória de curto e a de longo prazo. Essas estratégias propiciam o armazenamento dessas palavras, pois elas estarão se relacionando a outras já anteriormente adquiridas.

A análise dos traços semânticos pode ser extremamente útil na aprendizagem dos hipônimos e hiperônimos, sinônimos e antônimos. Essa atividade pode auxiliar a identificaçào daqueles traços distintivos existentes entre palavras que, à primeira vista, são consideradas sinônimas, mas que, na realidade, têm diferenças de emprego, tanto do ponto de vista retórico ou pragmático, quanto do ponto de vista da variação dialetal. Daí dizer-se que nào há sinônimos perfeitos. Quanto aos antônimos, a experiência pedagógica tem mostrado que é bem mais prático aprender, de uma só vez, uma palavra e seu oposto.

Os tipos de vocabulário que os indivíduos adquirem (ou esquecem) dependem, em parte, da faixa etária, da diversidade dos interesses, do volume e da história de leitura que esse indivíduo possui, e também dos métodos de ensino a que foi submetido, além das estratégias de aquisiçào que desenvolveu, ao longo das suas interaçòes lingüísticas. Especialmente relevantes também sào os tipos de relaçòes sociais que o indivíduo tem experienciado na sua convivência em comunidade.

\section{LEXIAS ORIUNDAS DE PROCESSOS FIGURATIVOS E LEXIAS COMPLEXAS}

Um tipo especial de vocabulário complexo sào as metáforas e as lexias oriundas de processos figurativos, como, por exemplo, as expressòes idiomáticas. A aquisiçào desse tipo de vocabulário envolve conhecimento cultural e social, conhecimento enciclopédico e, especialmente, conhecimento 
lexical razoável. A metáfora é comumente tida como específica da linguagem literária, mas é muito mais freqüente na linguagem falada do que se imagina. Sua manutenção no léxico da língua está muito relacionada aos sistemas sóciocultural e ideológico em que se vive. A aquisição desse tipo de vocabulário começa logo cedo, especialmente as metáforas de bases mais concretas. Evidentemente, quanto mais elaboradas, mais maturidade cognitiva, sóciocultural e lingüística exigem.

\section{AlguMAS ESPECIFICIDADES LEXICAIS DA LÍNGUA INGLESA - SUAS IMPLICAÇÕES NA APRENDIZAGEM DO VOCABULÁRIO DESSE IDIOMA}

Outro tipo especial de vocabulário são as palavras compostas. Para o aprendiz da língua estrangeira, essas lexias trazem um pouco de dificuldade porque exigem um conhecimento seguro dos termos que as compóem e o domínio efetivo do sistema sintático da língua. Na nossa prática de ensino, verificamos que nossos aprendizes de inglês, na qualidade de não-nativos, demonstram muita insegurança no uso desses termos, levando esses indivíduos a evitarem o emprego de palavras compostas, preferindo o uso de paráfrases, por exemplo, bag for sleeping no lugar de sleeping bag. Aliás, isso também ocorre com os phrasal verbs. Havendo insegurança, o aprendiz recorre a um verbo sinônimo não-frasal, por exemplo, to cause no lugar de to bring about.

Do ponto de vista da análise contrastiva, de acordo com Silveira (1997), as palavras compostas são de grande produtividade, tanto em português, como em inglês. Em ambos os idiomas, predominam a natureza semântica e as estruturas sintáticas mais características de cada língua."

É relevante considerar que a língua inglesa, como outras línguas germânicas, possui muitas palavras que, mesmo sendo percebidas pelos usuários normais e pelos aprendizes como palavras simples, são, na realidade, palavras compostas de termos que podem também ser usados como palavras isoladas. As palavras compostas em inglês ocorrem em todas as partes dos enunciados, com exceção dos artigos. Utilizamos aqui exemplos dados por Zandvoort (1972, p.277): goldsmith (ourives = substantivo); seasick (enjoado = adjetivo); myself (me, a mim mesmo = pronome); overcome (superar = verbo);

\footnotetext{
No português, um tipo de composto muito freqüente tra\%, naturalmente, o termo modificado (DND) antes do termo modificantc (D' $\mathrm{I}$ ) = halatra-thate, laranja-lima, rangue-frio, dedo-duro. No inglês, dá-se o contririo, a estrutura mais frequente dos compostos segue a ordem DT-DM = bourework, raincoat. notebook., roiking-chair, efi: (SIIVIIIRA, 1997)
} 
somewhere (em algum lugar = advérbio); into (em, para dentro de $=$ preposiçào); whenever (quando quer que, sempre que = advérbio e conjunção); beigh-bo (interjeição de desalento); twenty-two (vinte e dois = numeral).

Existe um fator que pode ter propiciado a grande facilidade de formação de palavras compostas no inglês: o monossilabismo. De fato, no inglês, boa parte do léxico constitui-se de palavras monossílabas: big, bag, bad, cat, dog, fit, slum, jam, fuss, job, fun, eat, sun, God, gold, go, get, moon, meat, nun, etc. Essa tendência se dá por um processo regular de evolução fonética do inglês, que vem se desenvolvendo há séculos e continua até hoje, especialmente pela via popular, segundo nos informa Jespersen (1948, p.165). Assim, omnibus virou bus e, mais recentemente, temos vet (veterinary); pub (public house); bike (bicycle); exam (examination), lab (laboratory), etc.

\section{CONTRIBUIÇÕES DA ANÁlisE CONTRASTIVA PARA A APRENDIZAGEM E AMPLIAÇÃO DE VOCABULÁRIO NO ENSINO INSTRUMENTAL DE LÍNGUAS}

A lingüística contrastiva tem suas raizes mais remotas na chamada lingüística comparativista que vigorou no século XIX. Apesar disso, trata-se de uma disciplina que terá sempre sua validade. Carl James (1981, p.iii), um importante lingüista aplicado britânico, defende que nada parece "de maior valor potencial para os professores de línguas do que a descrição comparativa e contrastiva da língua materna do aprendiz e da língua estrangeira". A legitimaçào da análise contrastiva se deu, na realidade, no seio da lingüística descritiva, em pleno estruturalismo. Segundo Vandressen (1988, p.75),

A lingüistica contrastiva é uma subárea da lingüística geral interessada em apontar similaridades e diferenças estruturais entre a língua materna (de um grupo de alunos) e a língua estrangeira, objeto de estudos. Visa principalmente delinear, com precisão, as estruturas que oferecem dificuldade de aprendizagem e as que, devido a similaridades com a língua materna, apresentam facilidade.

Mesmo tendo essas duas línguas - português e inglês - origens diversas (latina e anglo-germânica), verificamos que elas possuem elementos de acentuada similaridade no processo de formação de palavras e conseqüente ampliação dos seus acervos lexicais.

De fato, nas duas línguas, os recursos e os mecanismos de formação de palavras mais efetivos e atuantes sào aqueles "internos ao sistema, sempre prontos para entrar em processo e desencadear a formaçào de novas palavras", 
como assinala Carone (1986, p.36). Vejamos, pois, sumariamente, esses elementos básicos de formação de palavras.

Formas Livres = geram palavras simples

Formas livres + formas livres (composição) = que geram palavras compostas

Formas presas + formas livres = geram palavras derivadas (derivação prefixal)

Formas livres + formas presas = geram palavras derivadas (derivação sufixal)

Elementos de flexão = não geram palavras novas.

Os recursos mais produtivos para a formação de palavras, tanto no português, como no inglês, são a derivação e a composição. Existem também a abreviação, a reduplicação, a onomatopéia e a lexicalização de siglas, mas esses processos são de muito pouca fertilidade. Há, ainda, a conversão ${ }^{7}$, também chamada, em português, de derivaçào imprópria. Esse processo é razoavelmente produtivo e diversificado em português, como, por exemplo, em Vocêprecisa andar mais e Ela tem um andar provocante. A conversão, porém, é muitíssimo mais fértil em inglês, já que, pela própria índole deste idioma, os substantivos podem, com muita freqüencia, transformar-se em verbos e viceversa, como, por exemplo, em Love is all $\mathrm{e} I$ love you; He is swimming at the moment e Swimming is good for bealth. Além disso, em inglês, com muita freqüência, qualquer substantivo anteposto a outro, num grupo nominal, transforma-se num adjetivo. Vejam-se, por exemplo, os compostos car racing (corrida de carro) e racing car (carro de corrida).

\subsection{ESTUDO DOS PROCESSOS DE PREFIXAÇÃO E SUFIXAÇÃO EM PORTUGUÊS E EM INGLÊS - ANÁLISE CONSTRASTIVA COMO PROCEDIMENTO DE ENSINO}

Um dos tópicos que se prestam a procedimentos de análise contrastiva e que têm muito a contribuir para a ampliação de vocabulário na língua estrangeira é aquele referente à derivação, que compreende, por sua vez, os processos de prefixação e de sufixação. O procedimento inicial pode ser apresentar palavras das quais se possam retirar e listar os prefixos e sufixos e procurar os correspondentes em português, chamando a atenção para aqueles que são de origem latina, grega (bi-, byper-, re-;-ment, -ance, -ation, etc.) e os de

Há de se enfatizar, nessa tarefa de desenvolver no aluno uma certa consciência metalingǘstica na aprendizagem do inglês, o fenómeno da conversão, pois ela assume um papel muito importante na recepção de textos, com implicações semânticas importantes. O aprendiz deve se familiarizar com frases do tipo "Take my hand", "Give me a band" c "Hand me this book, please". 
origem nào-latina, ou seja, de origem germânica, gótica ou céltica (mis-, fore-, hood, -ful, etc.). Uma atividade interessante para dar mais significabilidade ao assunto é a organização de famílias de palavras, como se vê abaixo:

\begin{tabular}{|c|c|c|c|c|}
\hline VERBO & SUBSTANTIVO & ADJETIVO & ADVÉRBIO & $\begin{array}{c}\text { SUBSTANTIV0 } \\
\text { AGENTE }\end{array}$ \\
\hline to believe & belief & believing, believable & believingl' & believer \\
\hline to invent & invention & inventive & inventively & inventor \\
\hline
\end{tabular}

Com efeito, a montagem de várias famílias de palavras dará condição ao aprendiz de trabalhar com uma grande e variada quantidade de sufixos e prefixos. Mas, evidentemente, serão os exercícios para emprego de vocábulos dessas famílias de palavras em lacunas de frases, parágrafos, e textos mais longos que deverão ajudar a fixação das palavras na mente. Exemplo:

I think that you should involve all your friends in this seminar. This (involvement) is very important for your project. And besides, I would like you to pay close attention to some points. So, you should be very (attentive) to my explanation next class.

Convém salientar que esse tipo de exercício também contribui para desenvolver mecanismos de coerência e coesão textuais, como o da nominalização (to involve - involvement).

\subsection{OUTRA POSSIBILIDADE DE PROCEDIMENTOS CONTRASTIVOS: OS RADICAIS GREGOS E LATINOS EM PORTUGUÊS E EM INGLÊS}

Como se sabe, o ensino do inglês instrumental se relaciona mais ao uso de gêneros textuais que portam linguagem científica e tecnológica. Essa linguagem, por sua vez, trabalha com terminologias cujos radicais gregos e latinos são muito freqüentes. Aliás, reconheça-se, este assunto (radicais gregos e latinos) sempre foi negligenciado pelos professores de português, certamente por acharem que esses itens são aprendidos de forma incidental, assistemática. Por experiência própria, verifiquei que os jovens apreciam muito esse assunto, que é de extrema relevância para as disciplinas de cultura geral e mais ainda para aquelas de cultura técnica.

Em relação a esses radicais gregos e latinos, é importante frisar que eles são cognatos perfeitos, que apresentam apenas algumas alteraçòes na 
grafia e na pronúncia (bidro-, bydro-; crono-, chrono-, etc), e devem ser apresentados primeiro em português e depois em inglês. Obviamente, alguns deles são plenamente reconhecidos pelos alunos, dada a sua freqüência na vida cotidiana: termo- (termômetro); rino- (rinite), frater- (fraternal), etc. Uma das atividades que dão significado a esse conhecimento é dar-se primeiro a definiçào da palavra derivada para o aluno inferir a palavra, sem olhar o dicionário, obviamente. Vejam-se os exemplos

1. A treatment of some diseases or disfunctions in which the person is put into water in order to do exercises. (hydrotherapy)

2. Abnormal fear of staying in high places. (acrophobia)

Defendo que esse tipo de exercício e outros similares, envolvendo radicais, prefixos e sufixos gregos e latinos, devem ser dados aos alunos de ensino médio e superior não só em inglês, mas também, e principalmente, em português. Todos nós sabemos das carências dos nossos jovens em relaçào ao domínio da língua escrita formal padrão e, especialmente, à terminologia mais universalizada das áreas científicas do currículo escolar e acadêmico. Com essa abordagem, pode-se minimizar esse problema.

\section{CONSIDERAÇÕES FINAIS}

O ensino instrumental de línguas é uma modalidade de ensino que muito tem a contribuir para melhorar o desempenho dos nossos estudantes universitários e de cursos técnicos, no que respeita à leitura para estudo e trabalho. Entretanto, esse tipo de ensino, além de ser ofertado para poucos ${ }^{8}$, tem sido prejudicado pela defasagem de conhecimentos e habilidades básicas dos alunos na própria língua materna. Essa situaçào é, certamente, uma conseqüência do caos atualmente reinante no ensino de português. Há necessidade, portanto, de se redimensionar o ensino da gramática nas nossas escolas, sem prejudicar o desenvolvimento da leitura como prazer e como habilidade instrumental.

\section{REFERENCIAS}

CARONE, Flávia de B. Morfossintaxe. São Paulo: Ática, Série Fundamentos, 1986.

HATCH, Evelyn and BROWN, Cheryl. Vocabulary, Semantics and Language Education. Cambridge: Cambridge University Press, 1995

* O Projeto Nacional de Inglês Instrumental infelizmente não é mantido em muitas escolas e universidades brasileiras. Na minha regiäo, por exemplo, essa modalidade ainda resiste pelo esforço individual de alguns professores da UFAL, e do CEFEI-AL. Falta um apoio institucional e condiçōes materiais para o incremento da proposta. 
JAMES, Carl. Contrastive Anabsis. London: Longman, 1981.

JESPERSEN, Otto. Growth and Structure of the English Language. Bristol: Basil Blackwell Oxford, 1948.

KRASHEN, Stephen. Principles and Practice in Second Language Acquisition. Oxford: Pergamon Press, 1981.

LEFFA, Vilson J. Aspectos internos e externos da aquisição lexical. In: LEFFA, Vilson J. (Org.) As palavras e sua companhia. Pelotas: AL tB e Editora da Universidade Católica de Pelotas, 2000.

LEWWIS, Michael. Implementing the Lexical Approaib. London: LTP, 1997.

$$
\text { The Lexical Approach. London: LTP, } 1993 .
$$

PAIVA, Vera L. Menezes O. Ensino de vocabulário. In: DUTRA, D.P. \& MELLO, H. A gramática e o vocabulário no ensino de inglês: novas perspectivas. Belo Horizonte: Faculdade de Letras / UFMG, 2004 (Série Estudos Lingüísticos, 7). Disponível em wrvw.veramenezes.com.br.

SILVEIRA, M. Inez Matoso. Linguas estrangeiras: uma visão bistórica das abordagens, métodos e técnicas de ensino. Maceió/São Paulo: Catavento, 1999.

SILVEIRA, M. Palavras compostas em português e em inglês. Recife, Programa de PósGraduação em Letras e Lingüística, UFPE, 1997. (Monografia de Tese de circulação restrita).

UNGERER, Friedrich. An Introduction to Cognitive Linguistics. 2 edition. London: Longman, 2006.

VANDRESSEN, Paulino. Lingüistica contrastiva e ensino de línguas estrangeiras. In: BOHN. Hilário \& VANDRESSEN, Paulino (orgs). Tópicos de lingüística aplicada: o ensino de línguas estrangeiras. Florianópolis: Editora da UFSC, 1988.

ZANDVOORT, R.W. A Handbook of English Grammar: 6 edition. London: Longman, 1972. 